\title{
Quantitative Analysis of the Sustainable Development Capacity of Regional Water Resources: A case study of Sichuan Province
}

\author{
Xuedong Liang ${ }^{1}, \mathrm{Li}$ Yang ${ }^{1}$, Meng Ye ${ }^{1}$, and Guoying Deng ${ }^{1, *}$ \\ ${ }^{1}$ Sichuan University, Chengdu 610065, China
}

\begin{abstract}
Limited water resources have become a serious problem in recent decades. Based on previous research results, this article develops an index system to evaluate sustainable water resource development that includes a water resource condition system, a water resource development and utilization system, a water resource protection and management system, and a socio-economic system. A measurement model is then constructed based on a principal component analysis (PCA) -entropy weights-weighted average method to optimize the evaluation index system for dimensionality reduction, to assign weights to the principal component factors, and allow for a comprehensive evaluation of water resource sustainability. The measurement model is applied to an empirical analysis of sustainable water resource development in Sichuan Province from 2008 to 2017, from which it is found that coordinated sustainable regional water resource and social economic development can be achieved through rational exploitation, efficient utilization, and environmental water pollution control. This research could provide a reference for regional sustainable development of water resources and policy developments.
\end{abstract}

\section{Introduction}

Water is basic to the earth's survival and essential for socio-economic development. With the intensification of human activities, increasing populations, and rapid urbanization, global water shortages have been increasing exponentially, which was recognized in the 1992 Dublin declaration on Water and Sustainable Development resulting from the international conference on water and the environment (ICWE) [1]. At present, due to poor management, a series of problems such as low water use efficiency, serious water pollution, and deterioration of ecological environment have seriously affected the function of water resources, which further challenges the development and utilization of water resources. Therefore, we must thoroughly study the problems faced by regional water resources and explore efficient methods and principles to achieve sustainable and coordinated development of regional water resources and social economy.

\section{Literature review}

For the first time, the "Common Future" published by the World Commission on Environment and Development defined sustainable development; development that meets the needs of the present generation without compromising the ability of future generations to meet their needs [2]; with sustainable water resource development being as follows; in a certain spatial range, the water resource utilization that can meet the needs of the people of today, and does not pose a hazard to future generations in meeting their needs. In recent years, extensive and indepth research has been conducted on sustainable water resources from several different perspectives.

There have been three main foci in water resource sustainable research, one of which has been the ecological footprint associated with water resources. Rees and Wackernagel first proposed the ecological footprint model and then continued to improve it, thereby providing new methods for the quantitative analysis of sustainable water resources [3-5]. Zhang et al. developed an improved water ecological footprint model to measure water quantity and water quality supply and demand, which overcame the drawbacks in the traditional freshwater ecological footprint model [6].

Another research perspective has been based on the water footprint. Hoekstra was the first to propose the water footprint concept, which was defined as the amount of water needed to produce the products and services consumed by certain populations over time, and which provided a comprehensive and true accounting of the water needed to sustain the human consumption of products and services [7]. Using the Drivers, Pressures, State, Impact, Response model of intervention (DPSIR), $\mathrm{Yu}$ and Han built a water footprint index system for a time-space analysis of sustainable water resource use, which overcame the limitations associated with current year analyses [8].

A further research perspective for sustainable water use has been based on evaluation models. Zhou and Dai have each incorporated a different method of empowerment that is more objective and overcomes the

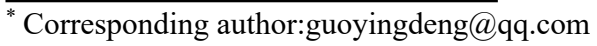


shortcomings of traditional indicator empowerment [9$10]$.

Therefore, there have been significant research achievements in sustainable water resource development. However, there remain flaws and shortcomings in these previous research methods and perspectives. For example, the ecological footprint and water footprint methods did not include social and economic development factors in the measurement systems, did not establish a corresponding model evaluation index system, and did not quantitatively assess sustainable water resource development. While the DPSIR method, which is based on an evaluation model, comprehensively considers economic, social, environmental, and policy factors, it is not suitable for regional sustainable development research as it only represents a traditional "responsive" concept to environmental protection. Further, most previous research has been focused only on water resource use. Given the deficiencies in previous studies, this article comprehensively considers the economic and social system, and innovatively builds a more comprehensive evaluation index system from the water resource condition system, the water resource development and utilization system, the water resource protection and management system, and the socio-economic system. Finally a water resource sustainability measurement model based on a principal component-entropy weightweighted average method is proposed to make a quantitative analysis of the sustainable development of water resources and tested in an empirical analysis of Sichuan Province.

\section{Materials and Methods}

\subsection{Indicator construction}

The determination of a sustainable water resource development level requires a comprehensive assessment of existing water resource conditions, water resource development and utilization efficiency, and protection and management efficiency, all of which affect sustainable socio-economic system development and the realization of a harmonious coexistence of the ecology, the economy, and the society. Under the principles of scientificity, comprehensiveness, salience, operability, and hierarchy, and based on previous research, the sustainable water resource development indicator system in this paper is divided into three layers: the target layer, the criterion layer, and the indicator layer. The target layer is the target required for sustainable water resource development. The criterion layer is made up of the water resource condition system, the water resource development and utilization system, the water resources protection and management system, and the socioeconomic system, for which there are 31 specific indicators, as shown in Table 1.

Table 1. Indicators for the sustainable water resource development.

\begin{tabular}{|c|c|c|c|}
\hline Criteria & Indicator & Definition & source \\
\hline \multirow{7}{*}{$\begin{array}{c}\text { Water } \\
\text { Resource } \\
\text { Condition } \\
\text { System } \\
\text { (G1) }\end{array}$} & Total water resources (G11) & Sum of surface water and non-repetitive groundwater & {$[8,9,10]$} \\
\hline & Per capita water resources $(\mathrm{G} 12)$ & $\begin{array}{l}\text { Resources total water resources/population, per capita water } \\
\text { resources }\end{array}$ & {$[10,11,13]$} \\
\hline & Surface water resources(G13) & $\begin{array}{l}\text { Dynamic precipitation of surface water through atmospheric } \\
\text { precipitation }\end{array}$ & {$[11,13]$} \\
\hline & Groundwater resources(G14) & Shallow groundwater volume directly linked to surface water & {$[10,11,13]$} \\
\hline & Annual precipitation(G15) & Characterizes the source of precipitation and climate wetness & {$[11,13]$} \\
\hline & Water module(G16) & Total water resource/area, water resource per unit area & {$[8,11,13]$} \\
\hline & Water production coefficient(G17) & $\begin{array}{l}\text { (total water resources/ area)/annual precipitation, } \\
\text { precipitation conversion rate }\end{array}$ & {$[8,11,13]$} \\
\hline \multirow{9}{*}{$\begin{array}{c}\text { Water } \\
\text { Resource } \\
\text { Develop- } \\
\text { ment and } \\
\text { Utilizati-on } \\
\text { System } \\
\text { (G2) }\end{array}$} & $\begin{array}{l}\text { Water Resource Development } \\
\text { Utilization(G21) }\end{array}$ & Total regional water supply/total water resources & {$[8,9]$} \\
\hline & $\begin{array}{c}\text { Surface water resource } \\
\text { utilization(G14) }\end{array}$ & Groundwater supply/groundwater & {$[8,10]$} \\
\hline & Groundwater extraction rate(G15) & Groundwater supply/groundwater & {$[8,10]$} \\
\hline & Industrial water quota(G24) & $\begin{array}{c}\text { Industrial water consumption/industrial GDP, reflecting } \\
\text { industrial water use efficiency }\end{array}$ & {$[11,8]$} \\
\hline & $\begin{array}{c}\text { Urban per capita daily water } \\
\text { consumption (G25) }\end{array}$ & $\begin{array}{c}\text { Characterizing the domestic water use efficiency of } \\
\text { urban residents }\end{array}$ & {$[8,14]$} \\
\hline & $\begin{array}{l}\text { Unit crop area water consumption } \\
\qquad(\mathrm{G} 26)\end{array}$ & Total agricultural water use / Total crop acreage & {$[8,14]$} \\
\hline & Ecological water use rate(G27) & $\begin{array}{l}\text { Eco-environmental water consumption/total water } \\
\text { consumption, co-environmental water use }\end{array}$ & {$[8,10,14]$} \\
\hline & Million GDP water use rate(G28) & $\begin{array}{l}\text { The amount of water consumed per million yuan produced in } \\
\text { that year }\end{array}$ & {$[8,10,14]$} \\
\hline & Reuse rate of water resources $(\mathrm{G} 29)$ & Repeat amount of water / total amount of water & {$[8,10]$} \\
\hline
\end{tabular}




\begin{tabular}{|c|c|c|c|}
\hline \multirow{8}{*}{$\begin{array}{c}\text { Water } \\
\text { Resource } \\
\text { Protecti-on } \\
\text { and } \\
\text { Manage- } \\
\text { ment } \\
\text { System } \\
\text { (G3) }\end{array}$} & $\begin{array}{l}\text { Industrial wastewater } \\
\text { discharge(G31) }\end{array}$ & $\begin{array}{c}\text { Represents the protection of water resources along with the } \\
\text { development of industry }\end{array}$ & {$[9,10,14]$} \\
\hline & $\begin{array}{l}\text { Industrial wastewater treatment } \\
\text { capacity }(\mathrm{G} 32)\end{array}$ & Represents the amount of wastewater treated daily & {$[11,13]$} \\
\hline & Sewage discharge(G33) & Represents the protection of water resources in people's life & {$[9,10,14]$} \\
\hline & Sewage treatment rate(G34) & Sewage treatment volume/sewage discharge & {$[10,12,14]$} \\
\hline & $\begin{array}{l}\text { Environmental pollution control } \\
\text { investment accounts for the } \\
\text { proportion of GDP }(G 35)\end{array}$ & $\begin{array}{l}\text { Represents the intensity of water environmental pollution } \\
\text { control }\end{array}$ & {$[10,12,13]$} \\
\hline & Total water conservation(G36) & Represents conservation and protection of water resources & {$[11,12,13]$} \\
\hline & $\begin{array}{c}\text { Water-saving irrigation } \\
\text { proportion }(\mathrm{G} 37)\end{array}$ & Water-saving irrigation area/total irrigation area & {$[8,11,13]$} \\
\hline & Forest cover rate $(\mathrm{G} 38)$ & Forest area/land area & {$[9,11,13]$} \\
\hline \multirow{7}{*}{$\begin{array}{l}\text { Socio- } \\
\text { Economic } \\
\text { System } \\
\text { (G4) }\end{array}$} & Total GDP(G41) & Regional GDP & {$[10,11,13]$} \\
\hline & GDP per capita(G42) & $\begin{array}{l}\text { The gross regional product/the number of permanent } \\
\text { residents, represents the socio-economic conditions }\end{array}$ & {$[8,10,14]$} \\
\hline & $\begin{array}{l}\text { Permanent Population } \\
\text { Density(G43) } \\
\end{array}$ & $\begin{array}{l}\text { resident population/area represents the water demand } \\
\text { pressure caused by the population }\end{array}$ & {$[10,14]$} \\
\hline & $\begin{array}{l}\text { Natural population growth } \\
\text { rate }(\mathrm{G} 44)\end{array}$ & $\begin{array}{l}\text { Birth rate - death rate, reflects the population development } \\
\text { rate }\end{array}$ & {$[9,14]$} \\
\hline & $\begin{array}{l}\text { Urban per capita disposable } \\
\text { income }(\mathrm{G} 45)\end{array}$ & Represents the living standards of urban residents & {$[11,13]$} \\
\hline & $\begin{array}{l}\text { Rural per capita disposable } \\
\text { income }(\mathrm{G} 46)\end{array}$ & Represents the living standards of rural residents & {$[11,13]$} \\
\hline & $\begin{array}{l}\text { The level of urbanization } \\
\text { (G47) }\end{array}$ & $\begin{array}{l}\text { Urban population/social population, measures the } \\
\text { urbanization degree }\end{array}$ & {$[8,9,10]$} \\
\hline
\end{tabular}

\subsection{Model Overview}

\subsubsection{Principal Component Analysis}

The essence of principal component analysis is to describe the original data information using less dimensions while maintaining as much of the original information as possible. Using dimensionality reduction, a few dominant and unrelated principal components are constructed to avoid problem correlation difficulties in the index data [15]. It is assumed that there are $m$ indicators for the principal component analysis and $n$ evaluation objects, thereby constituting an initial matrix of $m^{*} n$, of which the $j-$ th index of the $i-$ th evaluation object is set to $x_{i j}$. The calculation steps are as follows:

(1) Raw data standardization:

$$
\bar{x}_{i j}=\frac{X_{i j-\overline{x_{j}}}}{s_{j}}
$$

After normalizing the original data, a standardized matrix $Z$ is determined, where $\bar{x}_{j}$ is the average value of the $j-$ th indicator sample, and $s_{j}$ is the standard deviation of the $j-$ th indicator sample;

(2) Calculate the correlation coefficient matrix: $\mathrm{R}=$ $\left(r_{i j}\right)_{m \times m}$;

(3) From the characteristic equation $|\lambda E-R|=0$, calculate the eigenvalues $\lambda_{i}(i=1,2,3, \cdots, \mathrm{m})$ and the eigenvector $e_{i}(i=1,2,3, \cdots, \mathrm{m})$;
(4) Calculate the principal component contribution rate $Q_{i}$ and the cumulative contribution rate $Q$. When the current cumulative contribution rate of $i$ principal components reaches $85 \%$, the first $i$ principal components are extracted as new variables;

(5) Calculate the principal component load $a_{i j}$, which reflects the correlation between the principal component and the original indicator;

$$
a_{i j}=\sqrt{\lambda_{i}} e_{i j}
$$

(6) Finally, this method will calculate each principal component score. $F_{i}$ represents the principal component index formed by the linear combination of the original variables.

$$
\left\{\begin{array}{c}
F_{1}=a_{11} x_{1}+a_{12} x_{2}+a_{13} x_{3}+\cdots+a_{1 p} x_{m} \\
F_{2}=a_{21} x_{1}+a_{14} x_{2}+a_{15} x_{3}+\cdots+a_{2 p} x_{m} \\
F_{3}=a_{31} x_{1}+a_{32} x_{2}+a_{33} x_{3}+\cdots+a_{3 p} x_{m} \\
\cdots \cdots \cdots \\
F_{p}=a_{\mathrm{p} 1} x_{1}+a_{\mathrm{p} 2} x_{2}+a_{\mathrm{p} 3} x_{3}+\cdots+a_{p m} x_{m}
\end{array}\right.
$$

\subsubsection{Entropy Method}

The entropy weight method is an objective weighting method that eliminates the influence of subjective factors, for which a judgment matrix is built using the index values for each evaluation object. After the matrix is normalized, the index entropy is calculated based on the entropy definition, after which the entropy weight of each principal component is calculated. As entropy is a measure of the degree of disorder in a system, the smaller 
the indicator's information entropy, the greater the information provided, and the greater the role it plays in the overall evaluation. The specific calculation steps for the entropy weight are as follows:

(1) Build an index judgment matrix. There are $n$ measurement objects and $p$ principal component factors. Build the standardized matrix $\mathrm{R}=\left(f_{i j}\right)_{n \times p}(i=$ $1,2,3, \cdots, \mathrm{m})$ on the score for each principal component.

(2) Calculate the entropy and entropy weight of each principal component. By definition, the entropy $e_{j}$ and the entropy weight $w_{j}$ of the $\mathrm{j}$-th principal component factor are:

$$
\begin{gathered}
b_{i j}=\frac{f_{i j}+1}{\sum_{\mathrm{i}=1}^{n}\left(f_{i j}+1\right)} \\
e_{j}=-\frac{1}{\ln n} \sum_{i=1}^{n}\left[b_{i j} \ln b_{i j}\right] \\
w_{j}=\frac{1-e_{j}}{\sum_{j=1}^{m}\left(1-e_{j}\right)}
\end{gathered}
$$

The original expression for $b_{i j}$ was $b_{i j}=\frac{f_{i j}}{\sum_{i=1}^{n} f_{i j}}$; however, when $b_{i j}=0, \ln b_{i j}$ is meaningless; therefore, the original formula was revised to formula (4).

\subsubsection{Weighted average method}

The weighted average method objectively evaluates the comprehensive evaluation value of the measured object.The comprehensive evaluation value is summed by multiplying the principal component factor weight and the principal component factor score.

$$
\mathrm{y}=\sum_{j=1}^{p} w_{j} \times f_{j}
$$

where $y$ is the comprehensive evaluation value for the measured object, $w_{j}$ is the main component factor weight, $f_{j}$ is the main component factor score, and $\sum w_{j}=1,(j=1,2,3, \cdots, \mathrm{p})$.

\section{Case study}

\subsection{Study area and data source}

The Sichuan Basin is located between $27-34^{\circ} \mathrm{N}$ and 100 - $108^{\circ} \mathrm{E}$ and has abundant water resources. The main rivers are the Yangtze River and the Jinsha River, which together have more than 1400 tributaries such as the Yalong River, the Lancang River, and the Jialing River. The annual water runoff is about 300 billion cubic meters, ranking first in China. Therefore, because of the significant water resources in Sichuan Province, it is vital to quantitatively measure the sustainability of the water resource development.

All research data from 2008 to 2017 were sourced from the Sichuan Statistical Yearbook [11], the Water Resources Bulletin of Sichuan Province [12], the China Environmental Statistical Yearbook [13], and some relevant provincial statistics. The data for some indicators were derived from original data and formula conversions.

\subsection{Main component extraction}

This paper used SPSS 14.0 software to standardize the original data. As the principle of cumulative variance states that the contribution rate should be greater than $85 \%$, four main components that contained $90.38 \%$ of the sustainable water resource system information and one main components that contained $89.43 \%$ of the socioeconomic system information were extracted. From formula (1)-(3), five principal component scores were calculated.

The formulas for the four main sustainability water resource system components were:

$\left\{\begin{array}{c}F_{1}=-0.028 x_{1}-0.033 x_{2}-0.027 x_{3}+\cdots+0.085 x_{24} \\ F_{2}=0.16 x_{1}+0.157 x_{2}+0.16 x_{3}+\cdots+0.017 x_{24} \\ F_{3}=0.024 x_{1}+0.006 x_{2}+0.024 x_{3}+\cdots+0.057 x_{24} \\ F_{4}=-0.015 x_{1}-0.043 x_{2}-0.015 x_{3}+\cdots-0.065 x_{24}\end{array}\right.$

The formulas for the one principal sustainability socio-economic system components was:

$$
\left\{F_{1}=0.158 x_{1}+0.157 x_{2}-0.107 x_{3}+\cdots+0.158 x_{7}\right.
$$

\subsection{Determination of the Main Component Factor Weights}

The principal component decision matrix was obtained by bringing the 2008 - 2017 normalized values into the above principal component formulas. By combining formulae (4) - (6), the entropy and weights for the principal component

\begin{tabular}{|c|c|c|c|c|c|c|c|}
\hline \multirow{2}{*}{ Year } & \multirow{2}{*}{ Evaluation Level } & \multicolumn{2}{|c|}{ Sustainable capacity } & \multicolumn{2}{|c|}{$\begin{array}{l}\text { Sustainable capacity of } \\
\text { water resource system }\end{array}$} & \multicolumn{2}{|c|}{$\begin{array}{l}\text { Sustainable capacity of } \\
\text { socio-economic system }\end{array}$} \\
\hline & & Value & Rank & Value & Rank & Value & Rank \\
\hline 2008 & poor & -0.285 & 7 & -0.008 & 6 & -0.277 & 10 \\
\hline 2009 & poor & -0.437 & 9 & -0.152 & 8 & -0.205 & 8 \\
\hline
\end{tabular}
factors were obtained, as shown in Table 2.

Table 2. Principal component decision matrix and weights.

\begin{tabular}{|c|c|c|c|c|c|}
\hline & $\mathbf{F}_{\mathbf{1}}$ & $\mathbf{F}_{\mathbf{2}}$ & $\mathbf{F}_{\mathbf{3}}$ & $\mathbf{F}_{\mathbf{4}}$ & $\mathbf{F}_{\mathbf{5}}$ \\
\hline $\mathbf{W}_{\mathbf{J}}$ & 0.141 & 0.205 & 0.198 & 0.167 & 0.208 \\
\hline
\end{tabular}

Table 3. Measurement values for sustainable water resource development. 


\begin{tabular}{|l|l|cc|cc|cc|}
\hline 2010 & poor & -0.431 & 8 & -0.205 & 7 & -0.146 & 9 \\
2011 & poor & -0.783 & 10 & -0.679 & 10 & -0.103 & 7 \\
2012 & average & 0.031 & 5 & 0.074 & 4 & -0.043 & 6 \\
2013 & average & 0.191 & 3 & 0.167 & 3 & 0.015 & 5 \\
2014 & average & 0.155 & 4 & 0.063 & 5 & 0.092 & 4 \\
2015 & poor & -0.114 & 6 & -0.282 & 9 & 0.160 & 3 \\
2016 & high & 0.519 & 2 & 0.282 & 2 & 0.157 & 2 \\
2017 & very high & 1.162 & 1 & 0.821 & 1 & 0.342 & 1 \\
\hline
\end{tabular}

\subsection{Comprehensive Evaluation of the Sustainable Development Capacity}

In combination with formula (7), the principal component scores were multiplied with the weights for each year and then summed to calculate the measures for sustainable water resource development in Sichuan Province from 2008 to 2017 . Further, in order to more intuitively observe the sustainable development of water resources in Sichuan Province, the sustainable development of water resources is divided into four categories by cluster analysis method, namely very high sustainability, high sustainability, average sustainability and poor sustainability. The results are shown in Table 3.

\subsection{Analysis of evaluation results}

Overall, Sichuan Province's sustainable water resource development capacity was a fluctuate upward trend, the development status from 2008 to 2011 and 2015 was in a poor sustainability state; the development status from 2012 to 2014 was average sustainability; the development status in 2016 was high sustainability; the sustainable development status in 2017 was very high sustainability.

From the comprehensive analysis, the decline in sustainability in 2009, 2011 and 2015 mirrored the water resource fluctuation trends. As the water resources declined, the sustainable development capacity also declined. Therefore, when seeking sustainable socioeconomic development, it is vital to ensure that there are improvements in the ecological water replenishment efficiency and a strengthening of the water cycle.

\section{Conclusion}

This paper comprehensively considers the water resources condition system, water resources development and utilization system, water resources protection system, social economic system, establishes a more complete evaluation index system, and then proposes a principal component-entropy-weight-weighted average method. The evaluation method overcomes the defects of the measurement index system which is not comprehensive and the measurement method is qualitative, and makes the evaluation result more scientific and reasonable. The comprehensive evaluation of the sustainable development of water resources in Sichuan Province shows that industrial water use efficiency, wastewater, domestic sewage discharge, treatment investment, treatment purification capacity, and ecological water supply rate need to be the focus of sustainable development of water resources.

\section{References}

1. Anon, Dublin statement and report of the conference (1992)

2. Gro Harlem Brundtland, Environ. Conserv. 14, 291294 (1987)

3. W.E. Rees, Environ. Urban. 6, 121-130 (1992)

4. W.E. Rees, Popul. Env. 17, 195-215 (1996)

5. M. Wackernagel, W.E. Rees, Ecol. Ceon. 20, 3-24 (1997)

6. Y. Zhang, H.P. Zhang, F.S. Li, L. Guo, Resources Science 35, 1601-1610 (2013)

7. A.Y. Hoekstra, P.Q. Hung, Global Environ. Chang. 15, 45-56 (2004)

8. H.Z. Yu, M. Han, Journal of Natural Resources 32, 474-483 (2017)

9. L.L. Zhou, L. Wang, J. Yu, Resources Science 36, 913-921 (2014)

10. T.S. Dai., S.R. Sun, W.H. Zhao, B.Y. Gu, Resour. Environ. Yangtze Basin 18, 421-426 (2009)

11. Statistics Bureau of Sichuan, Sichuan Statistical Yearbook (2018)

12. Sichuan Provincial Water Resources Department, Water Resources Bulletin of Sichuan Province (2018)

13. State Statistics Bureau, China Statistical Yearbook on Environment (2018)

14. O. Mititelu-Ionuş, Pol. J. Environ. Stud. 26, 2095 2105 (2017)

15. S. Wold, K.Esbensen, P.Geladi, Chemometrics \& Intelligent Laboratory Systems 2, 37-52(1987) 